\title{
Foreign Direct Investment in a Small Open Economy and Global Trade Liberalization in Agriculture: A Note
}

\author{
Sarbajit Chaudhuri \\ University of Calcutta
}

\begin{abstract}
In a production structure reasonable for a developing economy this note shows that there may arise a conflict between the worldwide liberalized trade policies in agriculture, which raise the price of the economy's primary exportable commodity, and the inflow of foreign capital into the economy. However, if the economy strictly adheres to the different facets of the agricultural trade liberalization policies, e.g. the removal of the indirect farm subsidies, the paper argues that the possible conflict may be avoided. The paper provides a theoretical basis for the removal of the farm subsidies if the economy wants to develop its technologically more advanced sectors with an adequate supply of foreign capital.
\end{abstract}

- JEL Classifications: F10, F13, O19.

- Key words: Liberalized trade policy in agriculture, Foreign capital inflow, Rate of return on foreign capital, Fertilizer subsidy

\section{Introduction}

Foreign capital plays a prominent role in the development of developing countries. The inflow of foreign capital not only can help in lessening the scarcity of domestic capital but also can help in transferring improved technology of production to the host countries, boosting up of the economy's

\footnotetext{
*Corresponding address: Dr. Sarbajit Chaudhuri, Department of Economics, University of Calcltta, 56A, B.T. Road Kolkata 700050 India, 23 Dr. P.N. Guha Road, Belgharia, Kolkata 700083, India. Tel: 91-332541-0455 (R), 91-33-2557-5082 (C.U.), Fax: 91-33-2844-1436 E-mails: sarbajitch@ yahoo.com, s_jit@vsnl.net http://papers.ssrn.com/author=294419 (C2003-Center for International Economics, Sejong Institution, All Rights Reserved.
} 
export growth and hence improving the balance-of-payments position and generating additional employment opportunities utilizing the hitherto untapped local resources. Of the different types of foreign capital our focus in this paper will be on the foreign direct investment (FDI), which is generally sector-specific in nature. Multinational corporations (MNCs) are no benevolent institutions. They invest only with an eye to the profitability of investment in the sector in which they plan to invest. Naturally they are interested to invest in the technologically advanced sectors with high profitability. Several studies have pointed out that over the last decade or So the FDI to developing countries has increased considerably.

The multilateral agreement and the formation of the World Trade Organization (WTO), resultant of the Uruguay round of discussions, have brought about revolutionary changes in liberalizing international trade across countries whether developed or developing. Radical measures for reducing tariff barriers and completely doing away with non-tariff barriers to ensure freer global trade have already been undertaken in manufacturing commodities that are intensive in the use of capital or skilled labour. However, the attempt to subject agricultural commodities to disciplines similar to those that govern trade in manufactures has not so far been successful. Moreover, in agriculture, exports from developing countries remain severely hampered by massive domestic support and export subsidy programs in developed countries, by peak tariffs and difficulties in the implementation of the tariff quota system (UNCTAD, 1999, p 41).

The possibility of a conflict between tariff reforms in manufactures and the attraction of foreign capital in a developing economy is inevitable. It has been observed that some developing countries, notably the non-OECD countries, are relatively slow in carrying out tariff reforms compared to other countries, although they have opted for the policy of free trade as their development strategy and have been able to attract substantial amount of Foreign Direct Investment (FDI) during the last decade. The explanation is provided by the tariff-jumping theory ${ }^{1}$ that suggests a positive correlation between the amount of FDI in a country and the tariff rates imposed by it. There is no doubt that the major driving force behind FDI by the multinational corporations (MNCs) in the developing countries is the higher rate of return on their capital in these

${ }^{1}$ See for example, Motta (1992) and Yanagawa (1990) for details. 
countries vis-à-vis the international capital market. Countries with protected domestic markets are likely to attract foreign investment, ${ }^{2}$ but only for the purpose of jumping the tariff walls and reaping a good harvest by serving their markets directly. On the contrary, reductions of import tariffs imply larger volumes of imports, lower rates of return to capital and smaller amounts of FDI in these countries. The tariff-jumping argument is valid only if foreign capital enters into the import-competing sector of the host country. On the contrary, Chaudhuri and Mukherjee (2002) show that the positive correlation between tariff rates and foreign capital flows prevails even if foreign capital comes into the export sector of a developing economy and thus explain why some developing countries implement tariff reforms very slowly compared to others, even after formally choosing free trade as their development strategies, in a more general fashion than the existing tariff-jumping theory.

The WTO is now embarking upon a new round of negotiations on agricultural trade. Multilateral liberalization in the context of the WTO negotiations will primarily imply reduced protection of agriculture where the rates of protection are the highest, i.e. in developed countries. It will imply reduced protection against imports and reduced subsidies for domestic production, including reduced export subsidies. A new agreement may impose limitations on these policies and on the introduction of new protectionist policies in other developing countries. As multilateral liberalization in agriculture following the Uruguay round has been limited in scope and is still being phased in, there is not yet much direct evidence available to judge empirically the consequences of such liberalization (see Haug and Øygard 1999). However, if the result of reduced trade barriers and increased international competition are uniform in both developed or developing countries, the prices of the primary agricultural exports of the developing countries are likely to rise because of the probable reduction of the multilateral tariffs by the large trading countries and increase in their import demands. Model simulations of multilateral trade liberalization, e.g. (Hoekman and Anderson, 1999) are quite unanimous in predicting that such a liberalization would result in higher world market prices than otherwise for those goods currently being protected and subsidised.

The present paper explores the possibility of a conflict between multilateral

\footnotetext{
${ }^{2}$ Although the supply of foreign capital in an economy is positively related to the rate of return to capital in the host country the actual amount of foreign capital that is allowed to go into a developing economy in many cases is directly regulated by its government. In the process of liberalization the governments of these countries are allowing more and more foreign capital to enter into their economies. See Marjit (1994) in this context.
} 
trade liberalization programs in agriculture and FDI in a developing economy in a general equilibrium set-up. It shows that a small open economy, which is capital scarce and willing to attract foreign capital in the desired sectors, cannot continue with the policy of subsidization of the major agricultural inputs. In a production structure reasonable for a developing economy, the paper shows that the worldwide liberalized trade policies in agriculture that raise the price of the economy's primary exportable commodity may lower the rate of return on foreign capital employed in the other sector (s) of the economy thereby reducing the incentives of the foreign investors to invest in those sectors. Therefore, there may arise a conflict between trade liberalization in agriculture and the inflow of foreign capital in a developing economy. However, if the developing countries strictly adhere to the different facets of the agricultural trade liberalization policies, e.g. removal of the indirect farm subsidies, the paper argues that the possible conflict may be avoided. The paper, therefore, provides a theoretical basis for the removal of farm subsidies ${ }^{3}$ if the economy wants to develop its technologically more advanced sectors with an adequate supply of foreign capital.

\section{The Model}

We consider a small open economy consisting of three sectors. Sector 1 produces a primary agricultural product using labour and fertilizer. Sector 2 produces a specialized manufacturing product with the help of labour and foreign capital. Sector 3 is the traditional manufacturing sector, which produces its output using labour and domestic capital. So foreign capital is specific to sector 2 and domestic capital is a specific input in sector 3. However, labour is mobile among all the three sectors of the economy. Fertilizer used in the production of sector 1 is entirely imported at a price given internationally and supplied to the producers at a subsidized price. Owing to our small open economy assumption we consider all the three product prices to be given internationally. The economy described above roughly resembles a less developed country. Production functions exhibit constant returns to scale with diminishing marginal productivity to each factor, resources are fully utilized and markets are competitive. We assume that the economy exports commodities 1 and 2 and is a net importer of the traditional

\footnotetext{
${ }^{3}$ The major categories of agricultural subsidies are fertilizer, food, power, credit and irrigation. These subsidies not only put a heavy burden on the exchequer but also bring down an economy's welfare by distorting the domestic prices of agricultural commodities.
} 
manufacturing product (commodity 3). Finally, the import-competing sector is protected by a tariff.

The following symbols will be used in the equations.

$X_{i}=$ level of production of the $i$ th sector, $i=1,2,3$;

$a_{K i}=$ capital-output ratio in the $i$ th sector, $i=2,3$;

$a_{L i}=$ labour-output ratio in the $i$ th sector, $i=1,2,3$;

$a_{F 1}=$ fertilizer-output ratio in sector 1 ;

$P_{i}=$ world price of the $i$ th good, $i=1,2,3$;

$P_{F}=$ world price of fertilizer;

$S=$ ad-valorem rate of subsidy on fertilizer;

$P_{F}{ }^{*}=P_{F}(1-S)=$ the effective price of fertilizer to the producers of sector 1 ;

$T=$ ad-valorem rate of tariff on the import of good 3;

$P_{3}{ }^{*}=P_{3} \cdot(1+T)=$ tariff-inclusive or domestic price of commodity 3 ;

$W=$ wage rate of labour;

$R_{F}=$ return to foreign capital;

$R_{D}=$ return to domestic capital;

$L=$ fixed amount of supply of labour; $K_{D}=$ fixed stock of domestic capital;

$K_{F}=$ supply of foreign capital.

We assume that the supply of foreign capital, $K_{F}$, is a rising function of the rate of return to capital in sector 2 . This is because foreign capital would enter into the relevant industry of the economy only if its rate of return in this sector is higher than that prevailing in the international market. The higher the rate of return, the larger will be the amount of foreign capital entering the economy. ${ }^{4}$ So we have

$$
K_{F}=K_{F}\left(R_{F}\right) ; K_{F}^{\prime}(.)>0 .
$$

A general equilibrium of the system is represented by the following set of equations:

$$
\begin{gathered}
W \cdot a_{L 1}+P_{F}^{*} \cdot a_{F 1}=P_{1} \\
W \cdot a_{L 2}+R_{F} \cdot a_{K 2}=P_{2} \\
W \cdot a_{L 3}+R_{D} \cdot a_{K 3}=P_{3} \\
a_{L 1} \cdot X_{1}+a_{L 2} \cdot X_{2}+a_{L 3} \cdot X_{3}=L
\end{gathered}
$$

\footnotetext{
${ }^{4}$ See in this context, Datta Chaudhuri and Adhikari (1993) and Gupta (1994), who have also made this
} assumption but in a different context.). 


$$
\begin{gathered}
a_{K 2} \cdot X_{2}=K_{F}\left(R_{F}\right) \\
a_{K 3} \cdot X_{3}=K_{D}
\end{gathered}
$$

Equations (2)-(4) are the zero profitability conditions for the three sectors of the economy. On the other hand, equations (5)-(7) are the full-employment conditions of the three factors of production: labour, foreign capital and domestic capital.

We have seven equations (1-7) to solve for seven unknowns: $W, R_{F}, R_{D}, X_{1}, X_{2}$, $X_{3}$ and $K_{F}$. The system possesses the decomposition property. The three factor prices are determined from equations (2-4), independently of factor endowments. Once the factor prices are known factor coefficients are also known. $X_{1}, X_{2}$ and $X_{3}$ are then found from equations (5-7). Finally, $K_{F}$ is obtained from equation (1) when $R_{F}$ is known.

\section{A. Comparative Statics}

To study the effects of a change in $P_{1}$ (or $S$ ) (or $T$ ) on the factor prices, the supply of foreign capital into the economy and on the product-mix, after totally differentiating equations (2)-(4) we get

$$
\begin{gathered}
\theta_{L 1} \cdot \hat{W}=\hat{P}_{1}-\theta_{F 1} \hat{P}_{F}^{*} \\
\theta_{L 2} \cdot \hat{W}+\theta_{K 2} \cdot \hat{R}_{F}=0 \\
\theta_{L 3} \cdot \hat{W}+\theta_{K 3} \cdot \hat{R}_{D}=\hat{P}^{*}{ }_{3}
\end{gathered}
$$

where $\theta_{j i}$ denotes the distributive share of the $j^{\text {th }}$ factor in the $i$ th industry for $j$ $=L, K_{F} K_{D}, F ; i=1,2,3$ and " $\wedge$ " denotes a proportional change (see Jones (1965)).

Solving (2.1)-(4.1) by Cramer's rule we get the following.

$$
\begin{gathered}
\hat{W}=(1 / \Delta) \cdot\left[\theta_{K 2} \cdot \theta_{K 3} \cdot\left(\hat{P}_{1}-\theta_{F 1} \cdot \hat{P}_{F}^{*}\right)\right] \\
\hat{R}_{F}=-(1 / \Delta) \cdot\left[\theta_{L 2} \cdot \theta_{K 3} \cdot\left(\hat{P}_{1}-\theta_{F 1} \cdot \hat{P}_{F}^{*}\right)\right] \\
\hat{R}_{D}=(1 / \Delta) \cdot\left[\theta_{L 1} \cdot \theta_{K 2} \cdot P_{3}^{*}-\theta_{K 2 \cdot} \cdot \theta_{L 3} \cdot\left(\hat{P}_{1}-\theta_{F 1} \cdot \hat{P}_{F}^{*}\right)\right]
\end{gathered}
$$

where $\Delta=\theta_{L 1} \cdot \theta_{K 2} \cdot \theta_{K 3}>0$.

\section{An increase in the price of the primary exportable commodity}

In the regime of liberalized international trade and investment the prices of 
primary agricultural exports of the developing countries are expected to rise possibly owing to the multilateral tariff reductions by the large trading countries and the consequent increase in their import demands. It is easy to check from equations (8.1)-(8.3) that an increase in the price of the primary agricultural product, $P_{1}$, ceteris paribus, raises $W$ but lowers both $R_{F}$ and $R_{D}$. Actually as $W$ rises following an increase in $P_{1}, R_{F}$ falls to satisfy the zero profitability condition in the specialized manufacturing sector. This lowers the inflow of foreign capital in the economy since it is positively related to the rate of return, $R_{F}$. So we have the following proposition.

PROPOSITION 1: An increase in the price of the agricultural commodity lowers the supply of foreign capital to the host country.

Using (8.1) and (8.2) from equation (6) one can derive

$$
\hat{X}_{2}=-\left(\theta_{L 2} \cdot \theta_{K 3} / \Delta\right) \cdot\left(E+\sigma_{2}\right) \cdot\left(\hat{P}_{1}-\theta_{F 1} \cdot \hat{P}_{F}^{*}\right)
$$

where $E=\left(K_{F}^{\prime}(.) \cdot R_{F} / K_{F}().\right)$ is the elasticity of supply of foreign capital with respect to its rate of return in the host country and $E>0$.

From (9), it follows that $\hat{X}_{2}<0$ when $\hat{P}_{1}>0$. It should be noted that sector 2 contracts even when the supply of foreign capital is absolutely insensitive to its rate of return, $R_{F}$. This leads to the following proposition.

PROPOSITION 2: An increase in the price of the agricultural product reduces the level of production of the specialized manufacturing sector. The latter sector contracts even if an inflow of foreign capital is independent of its rate of return.

\section{A Reduction in Fertilizer Subsidy}

Trade liberalization in agriculture includes a gradual abolition of all direct and indirect farm subsidies. In the developing countries, producers in the agricultural sector get several essential inputs like fertilizer at highly subsidized prices. If the rate of fertilizer subsidy is reduced, ceteris paribus, $\hat{S}<0$ but $\hat{P}_{1}, \hat{T}=0$. Since $\hat{P}_{F}^{*}=-(S /(1-S)) . \hat{S}$, from $(8.2)$ we can write

$$
\hat{R}_{F}=-(1 / \Delta) \cdot\left[\theta_{L 2} \cdot \theta_{K 3} \cdot \theta_{F 1} \cdot(S /(1-S))\right] . \hat{S}>0 \text { if } \hat{S}<0
$$

From equation (1) it then follows that $K_{F}$ increases if $S$ decreases. From (9) it now follows that 


$$
\left.\hat{X}_{2}=-\left(\theta_{L 2} \cdot \theta_{K 3} / \Delta\right) \cdot\left(E+\sigma_{2}\right) \cdot(S /(1-S))\right] . \hat{S}>0 \text { if } \hat{S}<0
$$

So we have the following proposition.

PROPOSITION 3: A reduction in fertilizer subsidy (i) raises the return to foreign capital; (ii) raises the supply of foreign capital in the economy; and, (iii) leads to an expansion of the specialized manufacturing sector.

The intuitive explanation of the above results is fairly straightforward. A reduction in the rate of fertilizer subsidy pushes up the effective price of fertilizer to the producers. To satisfy the price-unit cost equality condition in the rural sector, the wage rate of labour, $W$ has to fall. As $W$ falls the rate of return to foreign capital, $R_{F}$ rises to satisfy the zero profitability condition in sector 2 , which in turn raises the supply of foreign capital into the economy, $K_{F}$. The producers in sector 2 will now adopt a less capital-intensive technique of production, which lowers the capital-output ratio $a_{K 2}$ since $W$ has fallen and $R_{F}$ has increased. A decrease in $a_{K 2}$ and an increase in $K_{F}$ ensure an expansion of the specialized manufacturing sector.

\section{Combined Effects of Reduction of Fertilizer Subsidy and Increase in Agricultural Price}

If the world price of the agricultural product increases and the ad-valorem subsidy rate on fertilizer decreases simultaneously we would have $\hat{P}_{1}>0$ and $\hat{S}<0$. It is worthwhile to mention that our small open economy cannot control $P_{1}$ but $S$ is its policy variable that can be manipulated according to the rate of increase in the agricultural price.

We consider the case where $\hat{S}=-\beta . \hat{P}_{1} ; \beta>0$.

Since $P_{F}^{*}=P_{F}(1-S)$, it follows that

$$
\begin{aligned}
& \hat{P}_{F}^{*}=-(S /(1-S)) \cdot \hat{S}=(\mathrm{S} /(1-S)) \cdot \beta . \hat{P}_{1} . \text { Hence, } \\
&\left(\hat{P}_{1}-\theta_{F 1} . \hat{P}_{F}^{*}\right)=\left\{\hat{P}_{1} \cdot\left[1-S .\left(1+\beta . \theta_{F 1}\right] /(1-S)\right\}\right.
\end{aligned}
$$

Using (11) from (8.2) and (9) we respectively get

$$
\begin{gathered}
\hat{R}_{F}=-(1 / \Delta) \cdot\left[\theta_{L 2} \cdot \theta_{K 3 \cdot} \cdot\left\{\hat{P}_{1} \cdot\left[1-S \cdot\left(1+\beta \cdot \theta_{F 1}\right] /(1-S)\right\}\right]\right. \\
\hat{X}_{2}=-\left(\theta_{L 2} \cdot \theta_{K 3} / \Delta\right) \cdot\left(E+\sigma_{2}\right) \cdot\left\{\hat{P}_{1} \cdot\left[1-S .\left(1+\beta \cdot \theta_{F 1}\right] /(1-S)\right\}\right]
\end{gathered}
$$

From (8.2.2) and (9.2) it follows that

$\hat{R}_{F}, \hat{X}_{2}>(=)(<) 0$ iff $\left((1-S) / S . \theta_{F 1}\right)<(=)(>) \beta$. 
An increase in $P_{1}$ lowers both $R_{F}$ and $X_{2}$. On the contrary, a reduction in fertilizer subsidy, $S$, raises them. When $\hat{S}=-\beta$. $\hat{P}_{1} ; \beta>0$, the combined effect would be an increase in both $R_{F}$ and $X_{2}$ if and only if $\beta>\left((1-S) / S . \theta_{F 1}\right)$. We are now interested in constructing a benchmark case where $P_{1}$ and $S$ both change in the same proportion but in the different directions. So if $\beta=1, \hat{R}_{F}, \hat{X}_{2}>(=)(<)$ 0 if and only if $S_{C}<(=)(>) S$ where $S_{C}$ is the critical value of the ad-valorem rate of subsidy on fertilizer and $S_{C}=\left\{1 /\left(1+\theta_{F 1}\right)\right\}$.

This leads to the following proposition.

PROPOSITION 4: An increase in the price of the agricultural product accompanied by a reduction in fertilizer subsidy, (i) raises the rate of return to foreign capital, (ii) raises the supply of foreign capital in the economy, and, (iii) leads to an expansion of the specialized manufacturing sector iff $\beta>\left((1-S) / S . \theta_{F 1}\right)$. In the benchmark case when $\beta=1$, the above results hold iff $S>S_{C}=\left\{1 /\left(1+\theta_{F 1}\right)\right\}$.

From (8.2) and (8.3) it is evident that any change in the rate of tariff imposed on the import-competing sector affects only $R_{D}$ and hence cannot affect the inflow of foreign capital. However, if foreign capital were employed in the importcompeting sector of the economy, a reduction in the tariff rate would have reduced the supply of foreign capital into the economy by lowering its rate of return.

\section{Concluding Remarks}

This paper in terms of a three sector full employment general equilibrium model has examined the possibility of arising a conflict between the global trade liberalization policy in agriculture and the inflow of foreign capital in a small open economy. The liberalized trade policy in agriculture, if followed by the large trading countries, is bound to raise the prices of the primary agricultural products, which in turn may lower the rate of return on foreign capital in a small open economy leading to a fall in the foreign capital inflow. This will seriously hamper the growth of the modern manufacturing sectors in the developing countries that rely on foreign capital inflow and technology. However, the paper points out that this possible conflict in the sphere of a small open economy may be avoided by withdrawal of the direct and indirect farm subsidies in the agricultural sector.

Even if a small open economy does not resort to liberalized trade measures external forces like an increase in the price of the primary agricultural commodity 
leads to a fall in the foreign capital inflow resulting in a contraction of its manufacturing sector, which relies heavily on the supply of foreign capital. We have shown that this untoward effect on the economy may be prevented by bringing down/ doing away with agricultural subsidies. In the process, the heavy burden on the exchequer and the loss of national welfare resulting from price distortions owing to subsidies would be lessened too. The paper, thus, provides a theoretical basis for the removal of farm subsidies if the economy wants to develop its technologically more advanced sectors with an adequate supply of foreign capital.

\section{Acknowledgements}

The presentation of the paper has been vastly improved from the editorial suggestions of Professor Jong Eun LEE, Managing Editor of this journal, to whom I must remain grateful. However, the usual disclaimer applies.

Received 31 March 2002, Accepted 17 September 2002

\section{References}

Chaudhuri, S., Mukherjee, U. (2002) Removal of Protectionism, Foreign Investment and Welfare in a Model of Informal Sector, Japan and the World Economy, 14(1), 101-16. Datta Chaudhuri, T., Adhikari, S. (1993) Free Trade Zones with Harris-Todaro Unemployment: A Note on Young-Miyagiwa, Journal of Development Economics, 41, 159-67.

Gupta, M.R. (1994) Duty-free Zone, Unemployment, and Welfare: A Note, Journal of Economics, 59(2), 217-236.

Haug, R., Øygard, R. (1999) Trade Liberalization in Agriculture: Consequences for Growth, Poverty Reduction and Environment in Developing Countries, Centre for International Environment and Development Studies, Agricultural University of Norway.

Hoekman, B., Anderson, K. (1999) Developing Country Agriculture and the New Trade Agenda. Paper presented at AEA Annual Meeting, 3-5 January 1999, at New York, NY.

Jones, R. W. (1965) The Structure of Simple General Equilibrium Models, Journal of Political Economy, 73, 551-72.

Marjit, S. (1994) On the Participation of Local Capital in a Foreign Enclave- A General Equilibrium Analysis, Journal of Economic Integration, 9, 489-501.

Motta, M. (1992) Multinational firm and the tariff-jumping argument: A game theoretic analysis with some unconventional conclusions, European Economic Review, 36(8),1557-1571.

UNCTAD (1999), Trade and Development Report 1999, Geneva: United Nations.

Yanagawa, N. (1990) Tariff Jumping Foreign Direct Investment, The Economic Studies

Quarterly, 41(4). 